\title{
Comportamento exploratório de ratos Wistar submetidos a um modelo animal de depressão
}

Tainá Pesente

Alex Hempel

Elvis Wisniewski

Miriam Salete Wilk Wisniewski

CADERNO DE RESUMOS

Fisisenectus . Unochapecó Ano 1 - Edição especial - 2013 p. 118

Tainá Pesente, acadêmica do curso de Fisioterapia da URI - campus de Erechim, Bolsista PIIC/URI, tainapsnt@hotmail.com

\section{Resumo}

Introdução: A depressão é um dos transtornos de humor no qual a sensação de tristeza, angústia e frustração interfere no cotidiano do individuo. 0 diagnóstico decorre de sinais e sintomas amplamente variados, sendo que a depressão afeta a afetividade, a conação e a psicomotricidade do paciente. Especificamente sobre as alterações na psicomotricidade, é frequente a presença de hipocinesia e/ou da acinesia (Cheniaux, 2013). Os modelos animais são ferramentas essenciais para se investigar a neurobiologia dessa síndrome que ainda não está totalmente esclarecida (Réus, Abelaira e Quevedo, 2013). Há diferentes protocolos indutores de estresse animal, sendo o CMS (Chronic Mild Stress) considerado um simulador no animal de situações próximas ao estresse humano. Objetivo: Analisar o comportamento exploratório de ratos Wistar submetidos ao protocolo de estresse crônico variado leve (CMS), através do número de cruzamentos e elevações. Metodologia: Foram utilizados 30 ratos Wistar, machos, divididos em dois grupos amostrais: controle e experimental, sendo o grupo experimental submetido a 40 dias de estresse por meio de estressores variados que compõe o CMS. Para analisar o comportamento exploratório dos animais foi realizado o teste de habilitação em campo aberto (Open Field Test), antes e após a indução do estresse, que consiste na avaliação do número de cruzamentos e elevações dos animais. Os dados obtidos foram testados inicialmente através dos testes de normalidade Kolmogorov-Smirnov e Shapiro-Wilk obtendo-se a distribuição normal da amostra. Para a análise estatística foi utilizado o Teste t de Student's para amostras independentes, sendo considerados significativos valores de $p<0,05$. Resultados: Animais do grupo controle apresentaram, em média, ao início do experimento, 21,4 \pm 12,69 e ao final 12,27 \pm 7,09 elevações, enquanto que o grupo experimental apresentou 20,13 \pm 7,80 e 17,73 \pm 7,63 , respectivamente. Com relação ao número de cruzamentos, em média, o grupo controle apresentou 77,87 $\pm 16,94$ e $70,8 \pm 22,3$, enquanto que o experimental $83,87 \pm 27,40$ e $78,0 \pm 24,13$. Comparando-se elevações e cruzamentos entre o grupo controle e experimental ao início e final do experimento, não foram encontrados resultados estatisticamente significativos. Considerações finais: Os resultados obtidos demonstraram que tanto os animais do grupo controle quanto do experimental, tanto em cruzamentos quanto em elevações, apresentaram menor movimentação em média ao final do experimento, sugerindo a presença de hipomobilidade, porém, quando comparados entre si, não apresentaram diferença estatisticamente significativa.

\section{Palavras-chave}

Transtorno depressivo. Estresse psicológico. Comportamento exploratório. 